This is an accepted manuscript of an article published by Taylor \& Francis in The Clinical Neuropsychologist on 16 Jun 2020, available online:

https://doi.org/10.1080/13854046.2020.1775892

\title{
NORMATIVE DATA FOR TEST OF LEARNING AND MEMORY IN AN \\ ECUADORIAN ADULT POPULATION
}

\begin{abstract}
Alberto Rodríguez-Lorenzanaa ${ }^{a}$, Silvia Núñez-Fernández ${ }^{b}$, Lila Angélica Adana Díaza Guido Mascialino ${ }^{a}$, Tarquino Yacelga Ponce ${ }^{a}$, Diego Rivera ${ }^{\mathfrak{c}}$, \& Juan Carlos ArangoLasprilla $^{\mathrm{d}, \mathrm{e}, \mathrm{f}^{*}}$
\end{abstract}

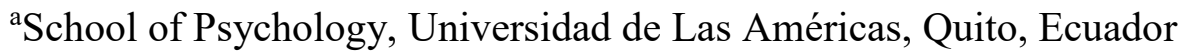
alberto.rodriguez@udla.edu.ec

lila.adana@udla.edu.ec guido.mascialino@udla.edu.ec tarquino.yacelga@udla.edu.ec

${ }^{b}$ Neurosciences doctoral program, University of Salamanca. Salamanca, Spain silay60@gmail.com

${ }^{\mathrm{c}}$ Departamento de Ciencias de la Salud, Universidad Pública de Navarra. Pamplona, España diegoriveraps@gmail.com

\author{
${ }^{\mathrm{d} B i o c r u c e s ~ B i z k a i a ~ H e a l t h ~ R e s e a r c h ~ I n s t i t u t e, ~ B a r a k a l d o, ~ S p a i n ~}$ \\ 'IKERBASQUE, Basque Foundation for Science, Bilbao, Spain \\ fDepartment of Cell Biology and Histology, University of the Basque Country \\ (UPV/EHU), Leioa, Spain \\ jcalasprilla@gmail.com
}

* Corresponding author at:

Psychology and Health Group

Biocruces Bizkaia Health Research Institute. Cruces University Hospital

IKERBASQUE. Basque Foundation for Science.

Plaza de Cruces s/n. 48903

Barakaldo. Bizkaia, Spain.

Phone: (34) 946006000 (Ext. 7963)

E mail: jcalasprilla@gmail.com

ORCID: https://orcid.org/0000-0002-7184-8311 


\begin{abstract}
Objective: The objective of this study was to develop norms for two neuropsychological tests of learning and memory in an Ecuadorian adult population. Method: 322 healthy individuals, ages between 18 and 84, were enrolled in the Metropolitan District of Quito. Participants were administered a comprehensive neuropsychological evaluation that included tests of learning and memory (Rey-Osterrieth Complex Figure Test [ROCF] and Hopkins Verbal Learning TestRevised [HVLT-R]). Backward stepwise multiple linear regression analyses were used to examine the influence of demographic variables age, education, and gender on test performance. Normative data was developed adjusting for demographic variables found to be significant in the final regression models. Results: The final multiple linear models revealed performance on tests of learning and memory worsened with age and improved as a function of education. A user-friendly Excel-based calculator is presented to calculate the $\mathrm{z}$ score and percentile automatically based on raw score and sociodemographic information. Conclusion: This is the first study that presents normative data for tests of learning and memory for an adult population in Ecuador. It is expected that these norms will help to improve the clinical practice of neuropsychology in Ecuador by limiting erroneous raw score interpretation and incrementing diagnostic accuracy.
\end{abstract}

Keywords: Regression models, normative data, memory and learning, Ecuador, adult. 


\section{Introduction}

Learning and memory are essential cognitive functions that allow human beings to assimilate and store information continuously (Bailey, Bartsch, \& Kandel, 1996). It is a dynamic process (Carrillo-Mora, 2010), interrelated with other cognitive functions, that grants the subject the ability to internalize and retain data obtained by perception of the external world (Etchepareborda \& Abad-Mas, 2005; Lezak, 2012). Learning and memory are often characterized according to its sequential phases: encoding, storage, and retrieval during immediate and delayed periods, as well as the time-permanence of the information (Strauss, Sherman, \& Spreen, 2006; Tirapu Ustárroz \& Grandi, 2016). These sequential processes and temporal stores, acting in unison, allow the experiences of the subject to be conscious and associated with other aspects of cognition and behavior (Atkinson \& Shiffrin, 1971).

In adults, impairment in learning and memory is the hallmark of several neurological disorders such Alzheimer's disease (Mayeux \& Stern, 2012; Verny \& Duyckaerts, 2020), traumatic brain injury (Dikmen et al., 2009; Hart \& Sander, 2017; Millis et al., 2001), stroke (Evans, Wong, Lawson, Withiel, \& Stolwyk, 2019; O’Brien et al., 2003; Sun, Tan, \& Yu, 2014), and multiple sclerosis (Chiaravalloti, Moore, Weber, \& DeLuca, 2019; DeLuca, Barbieri-Berger, \& Johnson, 1994; Minden, Moes, Orav, Kaplan, \& Reich, 1990) among others.

Several neuropsychological tools have been developed to assess learning and memory functioning across the lifespan (Mitrushina, Boone, Razani, \& D'Elia, 2005; Strauss et al., 2006). Two of the most commonly used measures worldwide to evaluate these functions are the ReyOsterrieth Complex Figure Test (ROCF; Rey, 1941) and the Hopkins Verbal Learning TestRevised (HVLT-R; Benedict, Schretlen, Groninger, \& Brandt, 1998). 
The HVLT-R is a measure of verbal learning and memory in an auditory modality (Benedict et al., 1998) and its psychometric properties have been well established in adult populations (Benedict et al., 1998; Shapiro, Benedict, Schretlen, \& Brandt, 1999; Woods et al., 2005). It has also been utilized in research with a variety of clinical populations, including traumatic brain injury, Alzheimer's disease, Parkinson's disease, epilepsy, and HIV-related cognitive impairment (Collins et al., 1999; De Almeida et al., 2017; Gonzalez-Palau et al., 2013; McLachlan, Pigott, Tellez-Zenteno, Wiebe, \& Parrent, 2010; Weintraub, Moberg, Culbertson, Duda, \& Stern, 2004; Woods et al., 2005). Use of the HVLT-R has extended to multiple countries within most regions of the globe, including Latin America, North America, Europe, Asia, and Africa (Arango-Lasprilla et al., 2015; Dellagi et al., 2009; Kanmogne et al., 2010; Rieu, BachoudLévi, Laurent, Jurion, \& Dalla Barba, 2006; Yepthomi et al., 2006).

The ROCF (Rey, 1941) is a test of learning and visual memory, proven to have good psychometric properties across several studies (Berry, Allen, \& Schmitt, 1991; Strauss et al., 2006), and utilized in research with a number of pathologies, including traumatic brain injury (Ashton, Donders, \& Hoffman, 2005; Schwarz, Penna, \& Novack, 2009), Alzheimer's disease (Bigler, Rosa, Schultz, Hall, \& Harris, 1989; Cherrier, Mendez, \& Dave, 1999), Parkinson's disease (Mohr et al., 1990), and multiple sclerosis (Schulz, Kopp, Kunkel, \& Faiss, 2006; Valentino et al., 2009) among others. Its extensive use, long trajectory, and good psychometric properties have made it a staple of clinical neuropsychological assessment (Lezak, 2012). The ROCF has also been utilized across many regions, including Latin America, Europe, and Asia (Caffarra, Vezzadini, Dieci, Zonato, \& Venneri, 2002; Palomo et al., 2013; Rivera et al., 2015; Watanabe et al., 2005). 
Norms for neuropsychological tests are abundant in English-speaking countries but less available for other regions (Fernández \& Abe, 2018; Mitrushina et al., 2005; Strauss et al., 2006). This is problematic because clinicians in non-English speaking countries must often resort to using English language norms to evaluate their patients. Because the norms they use are not language or culturally appropriate, this can lead to errors in the interpretation of the results of the tests administered (Arango-Lasprilla, Stevens, Morlett Paredes, Ardila, \& Rivera, 2017). Although some efforts to develop norms for Spanish-speaking populations have been previously undertaken (Cherner et al., 2007; Pontón et al., 1996), only until recently have large-scale studies been conducted in Spanish-speaking regions (Loureiro et al., 2018; Palomo et al., 2013; Peña-Casanova et al., 2009a; Rivera \& Arango-Lasprilla, 2017, Morlett et al., 2020) aimed at the standardization of neuropsychological tests in each country.

The main basis for this type of research is to improve the ability of clinicians to capture the true capacity of the individual, by using context-appropriate norms, in order to avoid erroneous interpretation of scores and potential misdiagnoses. Neuropsychology in Ecuador is currently in a state of growth, as evidenced by greater availability of services and increased research efforts (Ramos-Galarza, 2017). However, to the best of the authors' knowledge, there are currently no norms available for most neuropsychological tests in an adult Ecuadorian population. The objective of this research is to address this need by making available demographically- adjusted norms for both the HVLT-R and the ROCF in this population. The availability of this data is likely to improve the clinical practice of neuropsychology in the country, as interpretation of scores will more accurately reflect individual performance in assessment. 


\section{Method}

\subsection{Participants}

The sample consisted of 322 healthy individuals who were recruited from Quito, Ecuador. Participants' age ranged from 18 to 84 years $(\mathrm{M}=41.3, \mathrm{SD}=18.2)$. The majority were women (54.04\%), primarily urban $82.8 \%$, and education ranged from 2 to 25 years $(\mathrm{M}=13.2, \mathrm{SD}=4.6)$. The maximum error of sample size was $\approx .055$ (accuracy level $\approx 94.5 \%$ ). The maximum error was established using classical estimation assuming infinite (very large) population sizes, where the case of maximum uncertainty was assumed $(\pi=1-\pi=.5)$ and a confidence interval of $95 \%$ (Arrufat, Guàrdia-Olmos, \& Blanxart, 1999).

The sociodemographic characteristics of the participants (age, education, and gender) can be found in Table 1.

Insert Table 1

To be eligible to participate, individuals had to have met the following requirements: (a) were between 18 to 85 years of age, (b) were born and currently live in Ecuador, (c) spoke Spanish as their native language, (d) had completed at least 1 year of formal education, (e) according to self-report, were able to read and write at the time of evaluation, (f) scored $\geq 23$ on the Mini-Mental State Examination (MMSE; Folstein, Folstein, \& McHugh, 1975; Villaseñor-Cabrera, GuàrdiaOlmos, Jiménez-Maldonado, Rizo-Curiel, \& Peró-Cebollero, 2010), (g) scored $\leq 4$ on the Patient Health Questionnaire-9 (PHQ-9; Kroenke, Spitzer, \& Williams, 2001), and (h) scored $\geq 90$ on the Barthel Index (Mahoney \& Barthel, 1965). 
A self-report questionnaire was administered to collect information about the subjects' medical history and health status. Subjects were determined to be ineligible if they reported or endorsed the following: (a) history of neurological or psychiatric conditions, (b) history of alcohol abuse or other psychotropic substances (c) history of systemic disease (e.g., diabetes mellitus), (d) regular use of medications that may impact cognitive functioning, (e) severe visual and/or hearing deficit and/or f) history of developmental problems or learning disabilities. All participants were community volunteers who did not receive financial compensation for participation.

\subsection{Procedure}

The present study was conducted as part of a larger study to generate statistical normative data for a series of neuropsychological measures in Spanish-speaking populations (GuardiaOlmos, Peró-Cebollero, Rivera, \& Arango-Lasprilla, 2015; Rivera \& Arango-Lasprilla, 2017).

The Ethics Committee of the Universidad San Francisco de Quito approved the study. Participants were volunteers from the community recruited through announcements distributed in local business, community centers, and through the university staff. All the persons that showed interest in participating were contacted by a member of the research team, who explained the nature of the study and answered any questions that the person might have. People that agreed to participate signed the informed consent, according to the Helsinki Declaration, and then their sociodemographic data was collected followed by the application of screening tests to verify inclusion and exclusion criteria. The neuropsychological tests were applied to the participants that satisfied the criteria. The assessment lasted between 80 and 120 minutes and the tests were administered in Spanish. The research was conducted in the facilities of the Universidad de Las 
Américas, Quito. No compensation was provided for participation in the study. Data collection started on May 2017 and ended on March 2019.

\subsection{Measures}

The Hopkins Verbal Learning Test-Revised (HVLT-R; Brandt \& Benedict, 2001). The administration contains three free recall learning trials consisting of 12 semantically categorized words, followed by a 20 -minute delayed recall trial, concluding with a yes/no recognition trial. The yes/no recognition task has a total of 24 words, incorporating 12 words from the recall list, six words that are semantically related to the recall items but were not included in the initial trials, and six unrelated words. The HVLT-R yields several scores including a total recall, delayed recall, and recognition. The test has six forms with different word lists to avoid practice effects in repeated administration. In this study, the Spanish version of the HVLT-R form 5 was used because a pilot testing supported that all words included on the HVLT-R form 5 were known and used in Latin American Spanish-speaking countries (Arango-Lasprilla et al., 2015; Rivera et al., 2019).

Rey-Osterrieth Complex Figure Test (ROCF; Rey, 1941). The ROCF includes 18 elements, and the maximum score for each of the two tasks (copy and three-minute delayed recall) is 36. Two points are given when the element is correctly reproduced; one point when the reproduction is distorted or incomplete but placed properly, or complete but placed poorly; half a point is credited when the element is recognizable, but distorted or incomplete, and placed poorly. A zero score is given when the element is absent or is not recognizable (Osterrieth, 1944). In this study the Spanish version of the ROCF was used, which included a copy trial and three-minute delayed recall (Rey, 2009). 


\subsection{Statistical Analyses}

\subsubsection{Exploratory data analysis}

In the exploratory data analysis phase, means and standard deviations were computed for the HVLT-R (total recall, delayed recall, and recognition) and ROCF (copy and three-minute delayed recall) scores. Further Pearson correlations between the HVLT-R, ROCF scores and the sociodemographic (age, education, and gender) variables were computed.

\subsubsection{The effects of demographic variables and the derivation of normative data}

HVLT-R (total recall, delayed recall, and recognition) and ROCF (copy and three-minute delayed recall) scores were computed separately. The effects of demographic variables on each score were evaluated by means of multiple linear regression analyses. The full regression models included as predictors: age, age ${ }^{2}$, education, education ${ }^{2}$, gender, and all two-way interactions between these variables. Age and education were centered (= calendar age in years - mean age in the sample; education in years - mean education in the sample) before computing the quadratic age and education to avoid multicollinearity (Aiken, West, \& Reno, 1991). Squared terms of age and years of education were added in the full model to allow for quadratic effects between these independent variables and tests scores. Gender was dummy coded as man $=1$ and woman $=0$. The full regression model can be formally described as: $Y_{i}=B_{0}+B_{1} \cdot\left(A g e-\bar{x}_{A g e}\right)_{i}+B_{2}$.

$$
\left(\text { Age }-\bar{x}_{A g e}\right)_{i}^{2}+B_{3} \cdot\left(\text { Education }-\bar{x}_{E d u}\right)_{i}+B_{4} \cdot\left(\text { Education }-\bar{x}_{E d u}\right)_{i}^{2}+B_{5} \cdot \text { Gender }_{i}+
$$

$B_{k} \cdot$ Interactions $_{i}+\varepsilon_{i}$, with the subscript $i$ referring to the participants $\left(i=\left\{1,2, \ldots, n_{i}\right\}\right.$, and $n_{i}$ the number of participants), the subscript $k$ referring to the regression parameters $(k=\{1,2, \ldots$, $\mathrm{K}$ \}, and $\mathrm{K}=$ the number of fixed-effects in the model including the intercept), and the term Interactions $_{i}$ being a short-hand notation to refer to all two-way interactions between the fixed 
effects. The model assumes that the residuals $\varepsilon_{i}$ are normally distributed with mean 0 and variance $\sigma_{\varepsilon}^{2}$, i.e., $\varepsilon_{i} \sim N\left(0, \sigma_{\varepsilon}^{2}\right)$.

Independent variables that were not statistically significant in the multiple regression model were removed, and a reduced model was fitted again. A Bonferroni-corrected alpha-level of $0.005(=.05 / 10)$ was used. In the stepwise model-building procedure, no predictor was removed as long as it was also included in a higher order term in the model (Aiken et al., 1991). For all multiple linear regression models, the following assumptions were evaluated: (a) multicollinearity, by checking that the Variance Inflation Factor (VIF) was not greater than 10 and the collinearity tolerance values were not greater than 1 (Kutner, Nachtsheim, Neter, \& Li, 2005), (b) homoscedasticity, by grouping the participants into quartiles of the predicted scores and applying the Levene test on the residuals, (c) normality of the standardized residuals, by using Kolmogorov-Smirnov test, and (d) the existence of influential values, by calculating the maximum Cook's distance in the sample. The maximum Cook's distance value was subsequently related to an $F(p, n-p)$ distribution, where $p$ is the number of regression parameters (including the intercept) and $\mathrm{n}$ is the sample size. Influential values are considered when the obtained percentile value is equal or higher than 50 (Kutner et al., 2005). An alpha level of .005 was used in all analyses.

Using the final regression model that is obtained at the end of the stepwise procedure, normative data that are adjusted for demographic variables were established by means of a fourstep procedure (Rivera et al., 2019; Van Breukelen \& Vlaeyen, 2005; Van der Elst, van Boxtel, Van Breukelen, \& Jolles, 2006a,b): (a) The expected test score $\left(\hat{Y}_{i}\right)$ is computed based on the fixed effect parameter estimates of the established final regression model: $\hat{Y}_{i}=B_{0}+B_{1} X_{1 i}+B_{2} X_{2 i}+$ $\cdots+B_{K} X_{K i}$. (b) To obtain the residual value $\left(e_{i}\right)$, a subtraction between the raw score of the 
neuropsychological test $\left(Y_{i}\right)$ and the predicted value previously calculated was performed $\left(\hat{Y}_{i}\right)$, as shown in the following formula: $e_{i}=Y_{i}-\hat{Y}_{i}$. (c) Using the residual standard deviation $\left(S D_{e}\right)$ value provided by the regression model, residuals were standardized: $z_{i}=e_{i} / S D_{e}$. (d) Finally, using the standard normal cumulative distribution function, the exact percentile corresponding to the z-score previously calculated was obtained (if the model assumption of normality of the residuals was met in the normative sample), or via the empirical cumulative distribution function of the standardized residuals (if the standardized residuals were not normally distributed in the normative sample). This four-step process was applied to the HVLT-R (total recall, delayed recall, and recognition) and ROCF (copy and three-minute delayed recall) scores separately. Adjusted Rsquared values are provided for all final models. All analyzes were performed using SPSS Version 23 (IBM Corp., Armonk, NY) and R 3.4.2 for Windows (R Development Core Team, 2013).

\subsubsection{Calculator of Normative Data}

The four-step normative procedures explained above offer the clinician the ability to determine an exact percentile for a participant who has a specific score on the HVLT-R and ROCF scores. However, this method can be prone to human error due to the number of required computations by hand. To enhance user-friendliness, the authors created a calculator in Microsoft Excel using these steps in which the clinician must include the following information: raw score HVLT-R (total recall, delayed recall, and recognition) and ROCF (copy and three-minute delayed recall) scores, age, education, and gender to calculate the z score and percentile automatically. This tool is freely available for all users and may be downloaded at www.masked.com. 


\section{Results}

\subsection{Exploratory data analysis}

The mean (SD) for HVLT-R total recall, HVLT-R delayed recall, HVLT-R recognition, ROCF copy, and ROCF of three-minute delayed recall scores equaled to 21.69 (4.83), 7.68 (2.42), 10.94 (2.02), 30.38 (5.95), and 18.33 (7.69), respectively. Pearson correlations coefficients showed intercorrelations between HVLT-R (total recall, delayed recall, and recognition), ROCF (copy and three-minute delayed recall) scores and the sociodemographic variable education were significantly positive $(r$ 's $\geq .167 ; p$ 's $<.005)$. There was a significant negative correlation between the HVLT-R (total recall, delayed recall, and recognition), ROCF (copy and three-minute delayed recall) scores and the variable age $(r$ 's $\geq-.495 ; p$ 's $<.05)$. Finally, the variable gender did not correlate significantly with any score (see Table 2 ).

Insert Table 2

\subsection{Model assumptions}

The assumptions of multiple linear regression analysis were largely met for all final models. There was no multicollinearity (the VIF values in all models were at most 1.528 , and thus well below the threshold value $=10$ that is indicative for multicollinearity; collinearity tolerance values did not exceed the value of 1) or influential cases (the maximum Cook's distance value was 0.125 ; relating this value to an $F_{(2,320)}$ distribution yields percentile value 12 , which is well-below the threshold percentile value $=50$ that is indicative for the presence of influential cases). The Levene test suggested that there was no heteroscedasticity in all models except in the ROCF copy 
score. Standardized residuals of the models were normally distributed (as evaluated with the Kolmogorov-Smirnov test) except for HVLT-R recognition and ROCF copy.

\subsubsection{HVLT-R}

The final multiple linear regression models for HVLT-R total recall, delayed recall, and recognition scores were significant (see Table 3). HVLT-R total recall score was negatively influenced by age and increased linearly as a function of education. The amount of variance (adjusted for the number of predictors in the final model; adjusted $\mathrm{R}^{2}$ ) explained by these predictors was $27 \%$. HVLT-R delayed recall score was negatively influenced by age and increased linearly as a function of education. The interaction between age and education also affected the score, so that young people with more years of education scored higher than those with fewer years of education. However, as the age progresses, the performance of the people progressively equaled independently of the education (see Figure 1). The participant's gender also affected HVLT-R delayed recall score, such that women scored higher than men. The amount of variance explained by these predictors was 30\%. Finally, HVLT-R recognition score increased linearly as a function of education. Age, quadratic age, gender, and interactions did not affect the model. The amount of variance explained by these predictors was $2.5 \%$.

Insert Table 3

\subsubsection{ROCF}

The final multiple linear regression models for ROCF copy and ROCF three-minute delayed recall scores were significant (see Table 4). ROCF copy score was negatively influenced 
by quadratic age and increased linearly as a function of education, showing a subtle decrease of scores until 50 years of age and a steeper decrease of 50 to 80 years, with people with more years of education performing better than people with fewer years of education. ROCF three-minute delayed recall score was negatively influenced by age and increased linearly as a function of education (see Figure 2). The amount of variance explained by these predictors for ROCF copy and ROCF three-minute delayed recall scores were $22.4 \%$ and $30 \%$, respectively.

\section{Insert Table 4}

\section{Discussion}

The purpose of this study was to generate normative data for an adult Ecuadorian population ages 18 to 85 for two of the most common neuropsychological tests of learning and memory: the HVLT-R and the ROCF. The effect of sociodemographic variables, such as age, gender, and education, was also analyzed and considered accordingly when developing the norms.

Linear regression models for the HVLT-R explained 2.5 to $30 \%$ of the variance. The model for recognition recall explained the smallest amount, while the other two models (total and delayed recall) accounted for a similar range. Consistent with those results, Duff (2016) derived demographically corrected norms for the HVLT-R and found recognition to have the lowest variance explained of all other subtests by a ratio of approximately 3 to 1 . Results indicated age had a negative impact on total and delayed recall, which is in line with prior research on Latin American and other populations (Arango-Lasprilla et al., 2015; Ryan et al., 2020; Strauss et al., 2006; Vanderploeg et al., 2000). Interestingly, the impact of education was lessened in older adults 
for delayed recall, which could be related to lower sample size and reduced variance in older age ranges. Nevertheless, education maintained a linear and positive relationship with performance on all three models, consistent with results from Arango-Lasprilla et al. (2015), which found this relationship on 10 of the 11 countries surveyed in Latin America. Gender was only significantly and positively related to delayed recall, making it the only test for which all demographic variables were significant.

On the ROCF, regression models explained 22.4 to $30 \%$ of the variance. Age was negatively related to performance on both copy and three-minute delayed recall ROCF conditions. This relationship was quadratic in the copy condition, meaning that the decline in performance was more pronounced in older age groups. Consistent with prior research, performance on threeminute delayed recall was also positively related to education (Ardila, Rosselli, \& Rosas, 1989; Caffarra et al., 2002; Rivera et al., 2015). In this study, gender was not associated with ROCF performance. These findings are consistent with studies in the overwhelming majority of Latin American countries (Rivera et al. 2015), Spain (Peña-Casanova et al., 2009b), and Englishspeaking sample (e.g., Berry et al., 1991).

Both level of education and age were significantly related to performance on most models, which is not a surprising finding in light of well-established work in this area (Arango-Lasprilla et al., 2015; Duff, 2016; Kuslansky et al., 2004; Rivera et al., 2015; Strauss et al., 2006). Consequently, norms presented in this study are broken down both by age and education in data tables and of course considered in the calculator as well.

This study presents some strengths when compared to prior norming efforts in Latin America; for instance, the majority of the previous studies were done with small sample sizes (i.e. Allegri et al., 1997; Rosselli, Ardila, Florez, \& Castro, 1990), did not control for some important 
variables on the analyses such age, age ${ }^{2}$ education, education ${ }^{2}$ and gender, did not consider the interaction effects and the curvilinear relationships between predicted variables and neuropsychological scores (Arango-Lasprilla et al., 2015; Rivera et al., 2015), and/or reported normative data based on means and standard deviations (i.e. Beltrán Dulcey \& Solis-Uribe, 2012; Fernández \& Marcopulos, 2008). The most comprehensive norming effort for tests of learning and memory in Latin America was conducted by Arango-Lasprilla et al. (2015), which obtained normative information from 11 Latin American countries for the tests considered here, but Ecuador was not part of the sample. Given variations in performance between countries in that study, it is not clear that results from other Latin American countries would necessarily be applicable to Ecuador. Additionally, this study presents with a larger age distribution, collinearity was controlled for, and interaction effects were considered in the model. Lastly, the current study provides a calculator to derive norms instead of using tables.

\subsection{Limitations}

The results of this study should be interpreted considering the following limitations. First, the study was conducted solely in the Distrito Metropolitano de Quito, and the sample was mostly urban $(82.8 \%)$, with secondary (23\%) and post-secondary (48\%) education, so results should be generalized to other regions of the country with caution. Second, the influence of bilingualism was not considered either. Ecuador is a country with a diversity of languages and there is evidence that performance in neuropsychological tests for bilingual patients differs from that of monolinguals (Kohnert, Hernandez, \& Bates, 1998; Vega-Mendoza, West, Sorace, \& Bak, 2015). However, the percentage of bilingualism in Ecuador is limited, and more so in urban regions. Third, although the cross-validation technique was not used to generate models, the low sample-size error of the 
models permits statistical inferences to populations with similar characteristics to the study sample. Fourth, another limitation of the study is the failure to include a 30-minute delayed recall trial on the ROCF. Although delayed recall is important for many of the clinical populations in which these tests are used, it was not included in this study because the Spanish version only includes a three-minute delayed recall. Future studies with this population should include the 30 -minute delayed recall. Lastly, education in this study was measured using the number years of education. However, the quality of education could vary greatly between people from different regions and socioeconomic status and it is possible that this factor could also influence the performance on this test. For this reason, future studies should consider how to adequately capture quality of education (e.g., number of students per class, infrastructure, resources, etc.) in the analyses.

\subsection{Conclusion}

To the best of the author's knowledge, this is the first study to develop norms for both the HVLT-R and ROCF in an Ecuadorian adult population. Age and education were found to be strong predictors of performance on most models, and thus they were included in the demographic corrections where appropriate. A calculator is provided for the clinician to facilitate deriving normative scores with ease and decrease the possibility of user error when utilizing data tables. The current study is expected to improve the clinical practice of neuropsychology in Ecuador by limiting erroneous raw score interpretation and incrementing diagnostic accuracy due to the availability of norms derived from the appropriate population. 


\section{Founding Resource}

This research did not receive any specific grant from funding agencies in the public, commercial, or not - for- profit sectors.

\section{Conflict of interest}

The authors report not conflicts of interest.

Number of words in the manuscript without including first page and references:

4327 


\section{References}

Aiken, L. S., West, S. G., \& Reno, R. R. (1991). Multiple regression: Testing and interpreting interactions. Sage Publications.

Allegri, R. F., Villavicencio, A. F., Taragano, F. E., Rymberg, S., Mangone, C. A., \& Baumann, D. (1997). Spanish Boston naming test norms. The Clinical Neuropsychologist, 11(4), 416-420. doi:10.1080/13854049708400471

Arango-Lasprilla, J. C., Stevens, L., Morlett Paredes, A., Ardila, A., \& Rivera, D. (2017).

Profession of neuropsychology in Latin America. Applied Neuropsychology: Adult, 24(4), 318-330. doi:10.1080/23279095.2016.1185423

Arango-Lasprilla, J. C., Rivera, D., Garza, M. T., Saracho, C. P., Rodríguez, W., RodríguezAgudelo, Y., ... \& Perrin, P. B. (2015). Hopkins Verbal Learning Test- Revised: Normative data for the Latin American Spanish speaking adult population. NeuroRehabilitation, 37(4), 699-718. doi:10.3233/NRE-151286

Ardila, A., Rosselli, M., \& Rosas, P. (1989). Neuropsychological assessment in illiterates: Visuospatial and memory abilities. Brain and Cognition. doi:10.1016/02782626(89)90015-8

Arrufat, A. S., Guàdia-Olmos, J. G., \& Blanxart, M. F. (1999). Introducción a la estadística en Psicología (Vol. 27). Edicions Universitat Barcelona.

Ashton, V. L., Donders, J., \& Hoffman, N. M. (2005). Rey Complex Figure Test performance after traumatic brain injury. Journal of Clinical and Experimental Neuropsychology, 27(1), 55-64. doi:10.1080/138033990513636

Atkinson, R. C., \& Shiffrin, R. M. (1971). The control of short-term memory. Scientific American. Doi:10.1038/scientificamerican0871-82 
Bailey, C. H., Bartsch, D., \& Kandel, E. R. (1996). Toward a molecular definition of longterm memory storage. Proceedings of the National Academy of Sciences, 93(24), 1344513452. Doi:10.1073/pnas.93.24.13445

Beltrán Dulcey, C., \& Solıs-Uribe, G. (2012). Evaluación neuropsicológica en adolescentes: Normas para población de Bucaramanga. Revista Neuropsicologıa, Neuropsiquiatrıa y Neurociencias, 12(2), 77-93.

Benedict, R. H. B., Schretlen, D., Groninger, L., \& Brandt, J. (1998). Hopkins verbal learning test-Revised: Normative data and analysis of inter-form and test-retest reliability. Clinical Neuropsychologist, 12(1), 43-55. doi:10.1076/clin.12.1.43.1726

Berry, D. T. R., Allen, R. S., \& Schmitt, F. A. (1991). Rey-Osterrieth Complex Figure: Psychometric characteristics in a geriatric sample. Clinical Neuropsychologist, 5(2), 143-153. doi:10.1080/13854049108403298

Bigler, E. D., Rosa, L., Schultz, F., Hall, S., \& Harris, J. (1989). Rey-Auditory Verbal Learning and Rey-Osterrieth Complex Figure Design performance in Alzheimer's disease and closed head injury. Journal of Clinical Psychology, 45(2), 277-280. doi:10.1002/1097-4679(198903)45:2<277::AID-JCLP2270450216>3.0.CO;2-M

Brandt, J., \& Benedict, R. H. B (2001). Hopkins verbal learning test--revised: professional manual. Psychological Assessment Resources.

Caffarra, P., Vezzadini, G., Dieci, F., Zonato, F., \& Venneri, A. (2002). Rey-Osterrieth complex figure: Normative values in an Italian population sample. Neurological Sciences, 22(6), 443-447. doi:10.1007/s100720200003 
Carrillo-Mora, P. (2010). Sistemas de memoria: Reseña histórica, clasificación y conceptos actuales. Primera parte: Historia, taxonomía de la memoria, sistemas de memoria de largo plazo: La memoria semántica. Salud Mental, 33(1), 85-93.

Cherner, M., Suarez, P., Lazzaretto, D., Fortuny, L. A. I., Mindt, M. R., Dawes, S., ... \& Heaton, R. (2007). Demographically corrected norms for the Brief Visuospatial Memory Test-revised and Hopkins Verbal Learning Test-revised in monolingual Spanish speakers from the U.S.-Mexico border region. Archives of Clinical Neuropsychology, 22(3), 343-353. doi:10.1016/j.acn.2007.01.009

Cherrier, M. M., Mendez, M. F., \& Dave, M. (1999). Performance on the Rey-Osterrieth Complex Figure test in Alzheimer disease and vascular dementia. Neuropsychiatry, Neuropsychology and Behavioral Neurology, 12(2), 95-101.

Chiaravalloti, N. D., Moore, N. B., Weber, E., \& DeLuca, J. (2019). The application of Strategy-based Training to Enhance Memory (STEM) in multiple sclerosis: A pilot RCT. Neuropsychological rehabilitation, 1-24. doi:10.10808/09602011.2019.1685550

Collins, M. W., Grindel, S. H., Lovell, M. R., Dede, D. E., Moser, D. J., Phalin, B. R., ... \& McKeag, D. B. (1999). Relationship Between Concussion and Neuropsychological Performance in College Football Players. JAMA, 282(10), 964. doi:10.1001/jama.282.10.964

De Almeida, M., Kamat, R., Cherner, M., Umlauf, A., Ribeiro, C. E., De Pereira, A. P., ... \& Ellis, R. J. (2017). Improving detection of HIV-associated cognitive impairment: Comparison of the international HIV dementia scale and a brief screening battery. Journal of Acquired Immune Deficiency Syndromes, 74(3), 332-338. doi:10.1097/QAI.0000000000001224 
Dellagi, L., Ben Azouz, O., Johnson, I., Kebir, O., Amado, I., \& Tabbane, K. (2009). Tunisian adaptation of Hopkins Verbal Learning Test, Form 1. La Tunisie Medicale, 87(10), 670673.

DeLuca, J., Barbieri-Berger, S., \& Johnson, S. K. (1994). The Nature of Memory Impairments in Multiple Sclerosis: Acquisition versus Retrieval. Journal of Clinical and Experimental Neuropsychology, 16(2), 183-189. doi:10.1080/01688639408402629

Dikmen, S. S., Corrigan, J. D., Levin, H. S., MacHamer, J., Stiers, W., \& Weisskopf, M. G. (2009). Cognitive outcome following traumatic brain injury. Journal of Head Trauma Rehabilitation, 24(6), 430-438. doi:10.1097/HTR.0b013e3181c133e9

Duff, K. (2016). Demographically corrected normative data for the Hopkins Verbal Learning Test-Revised and Brief Visuospatial Memory Test-Revised in an elderly sample. Applied Neuropsychology: Adult, 23(3), 179-185. doi:10.1080/23279095.2015.1030019

Etchepareborda, M. C., \& Abad-Mas, L. (2005). Memoria de trabajo en los procesos básicos del aprendizaje. Revista de Neurología, 40(1), 79-83.

Evans, F. A., Wong, D., Lawson, D. W., Withiel, T. D., \& Stolwyk, R. J. (2019). What are the most common memory complaints following stroke? A frequency and exploratory factor analysis of items from the Everyday Memory Questionnaire-Revised. The Clinical Neuropsychologist, 1-14. doi:10.1080/13854046.2019.1652349

Fernández, A. L., \& Abe, J. (2018). Bias in cross-cultural neuropsychological testing: problems and possible solutions. Culture and Brain, 6(1), 1-35. doi:10.1007/s40167017-0050-2 
Fernández, A. L., \& Marcopulos, B. A. (2008). A comparison of normative data for the Trail Making Test from several countries: Equivalence of norms and considerations for interpretation. Scandinavian journal of psychology, 49(3), 239-246. doi:10.1111/j.14679450.2008.00637.x

Folstein, M. F., Folstein, S. E., \& McHugh, P. R. (1975). "Mini-mental state.” A practical method for grading the cognitive state of patients for the clinician. Journal of Psychiatric Research, 12(3), 189-198.

Gonzalez-Palau, F., Franco, M., Jimenez, F., Parra, E., Bernate, M., \& Solis, A. (2013). Clinical Utility of the Hopkins Verbal Test-Revised for Detecting Alzheimer's Disease and Mild Cognitive Impairment in Spanish Population. Archives of Clinical Neuropsychology, 28(3), 245-253. doi:10.1093/arclin/act004

Guàrdia-Olmos, J., Peró-Cebollero, M., Rivera, D., \& Arango-Lasprilla, J. C. (2015). Methodology for the development of normative data for ten Spanish-language neuropsychological tests in eleven Latin American countries. NeuroRehabilitation, 37(4), 493-499. doi:10.3233/NRE-151277

Hart, T., \& Sander, A. (2017). Memory and traumatic brain injury. Archives of physical medicine and rehabilitation, 98(2), 407-408. doi:10.1016/j.apmr.2016.09.112

IBM Corp. (2015). IBM SPSS Statistics for Windows, Version 23.0. Armonk, NY: IBM Corp. Kanmogne, G. D., Kuate, C. T., Cysique, L. A., Fonsah, J. Y., Eta, S., Doh, R., ... \& Njamnshi, A. K. (2010). HIV-associated neurocognitive disorders in sub-Saharan Africa: a pilot study in Cameroon. BMC Neurology, 10(1), 60. doi:10.1186/1471-2377$10-60$ 
Kohnert, K. J., Hernandez, A. E., \& Bates, E. (1998). Bilingual performance on the Boston Naming Test: Preliminary norms in Spanish and English. Brain and Language, 65(3), 422-440. doi:10.1006/brln.1998.2001

Kroenke, K., Spitzer, R. L., \& Williams, J. B. (2001). The PHQ-9: validity of a brief depression severity measure. Journal of General Internal Medicine, 16(9), 606-613. doi:10.1046/j.1525-1497.2001.016009606.x

Kuslansky, G., Katz, M., Verghese, J., Hall, C. B., Lapuerta, P., LaRuffa, G., \& Lipton, R. B. (2004). Detecting dementia with the Hopkins Verbal Learning Test and the Mini-Mental State Examination. Archives of Clinical Neuropsychology: The Official Journal of the National Academy of Neuropsychologists, 19(1), 89-104. doi:10.1093/arclin/19.1.89

Kutner, M. H., Nachtsheim, C. J., Neter, J., \& Li, W. (2005). Applied linear statistical models (5th ed.). New York: McGraw Hill.

Lezak, M. D. (2012). Neuropsychological assessment (5th ed.). New York: Oxford University Press.

Loureiro, C., Garcia, C., Adana, L., Yacelga, T., Rodriguez-Lorenzana, A., \& Maruta, C. (2018). Use of the Montreal Cognitive Assessment (MoCA) in Latin America: a systematic review. Revista de Neurologia, 66(12), 397-408.

Mahoney, F. I., \& Barthel, D. W. (1965). Functional evaluation: The Barthel Index: A simple index of independence useful in scoring improvement in the rehabilitation of the chronically ill. Maryland State Medical Journal, 14, 61-65.

Mayeux, R., \& Stern, Y. (2012). Epidemiology of Alzheimer disease. Cold Spring Harbor Perspectives in Medicine, 2(8). doi.10.1101/cshperspect.a006239 
McLachlan, R. S., Pigott, S., Tellez-Zenteno, J. F., Wiebe, S., \& Parrent, A. (2010). Bilateral hippocampal stimulation for intractable temporal lobe epilepsy: Impact on seizures and memory. Epilepsia, 51(2), 304-307.doi:10.1111/j.1528-1167.2009.02332.x

Millis, S. R., Rosenthal, M., Novack, T. A., Sherer, M., Nick, T. G., Kreutzer, J. S., ... \& Ricker, J. H. (2001). Long-term neuropsychological outcome after traumatic brain injury. The Journal of Head Trauma Rehabilitation, 16(4), 343-355.doi:10.1097 / 00001199-200108000-00005

Minden, S. L., Moes, E. J., Orav, J., Kaplan, E., \& Reich, P. (1990). Memory impairment in multiple sclerosis. Journal of Clinical and Experimental Neuropsychology, 12(4), 566586. doi:10.1080/01688639008401002

Mitrushina, M., Boone, K. B., Razani, J., \& D'Elia, L. F. (2005). Handbook of normative data for neuropsychological assessment. Oxford University Press.

Mohr, E., Juncos, J., Cox, C., Litvan, I., Fedio, P., \& Chase, T. N. (1990). Selective deficits in cognition and memory in high-functioning Parkinsonian patients. Journal of Neurology Neurosurgery and Psychiatry, 53(7), 603-606.doi: 10.1136/jnnp.53.7.603

Morlett Paredes, A., Gooding, A., Artiola i Fortuny, L., Rivera Mindt, M., Suárez, P., Scott, T. M., ... \& Marquine, M. J. (2020). The state of neuropsychological test norms for Spanish-speaking adults in the United States. The Clinical Neuropsychologist, 1-17. doi:10.1080/13854046.2020.1729866

O’Brien, J. T., Erkinjuntti, T., Reisberg, B., Roman, G., Sawada, T., Pantoni, L., ... \& DeKosky, S. T. (2003). Vascular cognitive impairment. Lancet Neurology. doi:10.1016/S1474-4422(03)00305-3 
Osterrieth, P. A. (1944). Le test de copie d'une figure complexe; contribution à l'étude de la perception et de la mémoire [Test of copying a complex figure; contribution to the study of perception and memory]. Archives de Psychologie, 30, 206-356.

Palomo, R., Casals-Coll, M., Sánchez-Benavides, G., Quintana, M., Manero, R. M., Rognoni, T., ... \& Peña-Casanova, J. (2013). Spanish normative studies in young adults (NEURONORMA young adults project): Norms for the Rey-Osterrieth Complex Figure (copy and memory) and Free and Cued Selective Reminding Test. Neurología, 28(4), 226-235. doi:10.1016/j.nrleng.2012.03.017

Peña-Casanova, J., Blesa, R., Aguilar, M., Gramunt-Fombuena, N., Gómez-Ansón, B., Oliva, R., ... \& Sol, J. M. (2009b). Spanish multicenter normative studies (NEURONORMA project): Methods and sample characteristics. Archives of Clinical Neuropsychology, 24(4), 307-319. doi:10.1093/arclin/acp027

Peña-Casanova, J., Quiñones-Úbeda, S., Gramunt-Fombuena, N., Quintana, M., Aguilar, M., Molinuevo, J. L., ... \& Antúnez, C. (2009a). Spanish Multicenter Normative Studies (NEURONORMA Project): norms for the Stroop color-word interference test and the Tower of London-Drexel. Archives of Clinical Neuropsychology, 24(4), 413-429. doi:10.1093/arclin/acp043.

Pontón, M. O., Satz, P., Herrera, L., Ortiz, F., Urrutia, C. P., Young, R., ... \& Namerow, N. (1996). Normative data stratified by age and education for the Neuropsychological Screening Battery for Hispanics (NeSBHIS): Initial report. Journal of the International Neuropsychological Society, 2(2), 96. doi:10.1017/S1355617700000941 
R Development Core Team (2013). R: A language and environment for statistical computing. Vienna, Austria: R Foundation for Statistical Computing. Retrieved from http://www.Rproject.org/

Ramos-Galarza, C. (2017). El Resurgir de la neurociencia Ecuatoriana: La Revista Ecuatoriana De Neurología. Revista Ecuatoriana de Neurología, 26(3), 187-190.

Rey, A. (1941). L'examen psychologique dans les cas d'encephopathie traumatique (The psychological examination of cases of traumatic encephalopathy). Archives de Psychologie, 28, 286-340.

Rey, A. (2009). REY: Test de copia de una figura compleja. Madrid: TEA ediciones.

Rieu, D., Bachoud-Lévi, A.-C., Laurent, A., Jurion, E., \& Dalla Barba, G. (2006). French adaptation of the Hopkins Verbal Learning Test. Revue Neurologique, 162(6-7), 721728.

Rivera, D., \& Arango-Lasprilla, J. C. (2017). Methodology for the development of normative data for Spanish-speaking pediatric populations. NeuroRehabilitation, 41(3), 581-592. doi:10.3233/NRE-172275

Rivera, D., Olabarrieta-Landa, L., Brooks, B. L., Ertl, M. M., Benito-Sánchez, I., Quijano, M. C., ... \& Arango-Lasprilla, J. C. (2019). Multivariate base rates of low scores on tests of learning and memory among Latino adult populations. Journal of the International Neuropsychological Society, 25(8), 834-844. doi:10.1017/S135561771900050X

Rivera, D., Olabarrieta-Landa, L., Van der Elst, W., Gonzalez, I., Rodríguez-Agudelo, Y., Aguayo Arelis, A., ... \& Arango-Lasprilla, J. C. (2019). Normative data for verbal fluency in healthy Latin American adults: Letter $M$, and fruits and occupations categories. Neuropsychology, 33(3), 287. doi: 10.1037 / neu0000518 
Rivera, D., Perrin, P. B., Morlett-Paredes, A., Galarza-Del-Angel, J., Martínez, C., Garza, M. T., ... \& Arango-Lasprilla, J. C. (2015). Rey-Osterrieth Complex Figure-copy and immediate recall: Normative data for the Latin American Spanish speaking adult population. NeuroRehabilitation, 37(4), 677-698. doi:10.3233/NRE-151285

Rosselli, M., Ardila, A., Florez, A., \& Castro, C. (1990). Normative data on the Boston Diagnostic Aphasia Examination in a Spanish-speaking population. Journal of Clinical and Experimental Neuropsychology, 12(2), 313-322. doi:10.1080/01688639008400977

Ryan, J., Woods, R. L., Murray, A. M., Shah, R. C., Britt, C. J., Reid, C. M., ... \& Trevaks, R. E. (2020). Normative performance of older individuals on the Hopkins Verbal Learning Test-Revised (HVLT-R) according to ethno-racial group, gender, age and education level. The Clinical Neuropsychologist, 1-17. doi:10.1080/13854046.2020.1730444

Schulz, D., Kopp, B., Kunkel, A., \& Faiss, J. H. (2006). Cognition in the early stage of multiple sclerosis. Journal of Neurology, 253(8), 1002-1010. doi:10.1007/s00415-0060145-8

Schwarz, L., Penna, S., \& Novack, T. (2009). Factors contributing to performance on the Rey complex figure test in individuals with traumatic brain injury. Clinical Neuropsychologist, 23(2), 255-267. doi:10.1080/13854040802220034

Shapiro, A. M., Benedict, R. H. B., Schretlen, D., \& Brandt, J. (1999). Construct and Concurrent Validity of the Hopkins Verbal Learning Test - Revised. The Clinical Neuropsychologist, 13(3), 348-358. doi:10.1076/clin.13.3.348.1749 
Strauss, E., Sherman, E. M. S., \& Spreen, O. (2006). A compendium of neuropsychological tests: Administration, norms, and commentary (3rd ed.). New York, NY: Oxford University Press.

Sun, J., Tan, L., \& Yu, J. (2014). Post-stroke cognitive impairment: epidemiology, mechanisms and management. Annals of Translational Medicine, 2(8), 80. doi:10.3978/j.issn.2305-5839.2014.08.05

Tirapu Ustárroz, J., \& Grandi, F. (2016). Sobre la memoria de trabajo y la memoria declarativa: propuesta de una clarificación conceptual. Cuadernos de NeuropsicologíaPanamerican Journal of Neuropsychology, 10(3), 13-31. doi:/10.7714/CNPS/10.3.201

Valentino, P., Cerasa, A., Chiriaco, C., Nisticò, R., Pirritano, D., Gioia, M., ... \& Quattrone, A. (2009). Cognitive deficits in multiple sclerosis patients with cerebellar symptoms. Multiple Sclerosis Journal, 15(7), 854-859. doi:10.1177/1352458509104589

Vanderploeg, R. D., Schinka, J. A., Jones, T., Small, B. J., Borenstein Graves, A., \& Mortimer, J. A. (2000). Elderly Norms for the Hopkins Verbal Learning Test-Revised. The Clinical Neuropsychologist, 14(3), 318-324. doi:10.1076/13854046(200008)14:3;1-P;FT318

Van Breukelen, G. J., \& Vlaeyen, J. W. (2005). Norming clinical questionnaires with multiple regression: The Pain Cognition List. Psychological assessment, 17(3), 336. doi:10.1037 / 1040-3590.17.3.336

Van Der Elst, W., Van Boxtel, M. P., Van Breukelen, G. J., \& Jolles, J. (2006a). Normative data for the Animal, Profession and Letter M Naming verbal fluency tests for Dutch speaking participants and the effects of age, education, and sex. Journal of the 
International Neuropsychological Society, 12(01), 80-89. doi:10.1017 / S1355617706060115

Van der Elst, W., van Boxtel, M. P., van Breukelen, G. J., \& Jolles, J. (2006b). The Letter Digit Substitution Test: normative data for 1,858 healthy participants aged 24-81 from the Maastricht Aging Study (MAAS): influence of age, education, and sex. Journal of Clinical and Experimental Neuropsychology, 28(6), 998-1009. doi:10.1080/13803390591004428

Vega-Mendoza, M., West, H., Sorace, A., \& Bak, T. H. (2015). The impact of late, nonbalanced bilingualism on cognitive performance. Cognition, 137, 40-46.

doi:10.1016/j.cognition.2014.12.008

Verny, M., \& Duyckaerts, C. (2020). Cognitive deficit, and neuropathological correlates, in the oldest-old. Revue Neurologique. doi:10.1016/j.neurol.2020.01.355

Villaseñor-Cabrera, T., Guàrdia-Olmos, J., Jiménez-Maldonado, M., Rizo-Curiel, G., \& Peró-Cebollero, M. (2010). Sensitivity and specificity of the Mini-Mental State Examination in the Mexican population. Quality and Quantity, 44(6), 1105-1112. doi:10.1007/s11135-009-9263-6

Watanabe, K., Ogino, T., Nakano, K., Hattori, J., Kado, Y., Sanada, S., \& Ohtsuka, Y. (2005). The Rey-Osterrieth Complex Figure as a measure of executive function in childhood. Brain and Development, 27(8), 564-569. doi:10.1016/j.braindev.2005.02.007

Weintraub, D., Moberg, P. J., Culbertson, W. C., Duda, J. E., \& Stern, M. B. (2004). Evidence for impaired encoding and retrieval memory profiles in Parkinson disease. Cognitive and Behavioral Neurology: Official Journal of the Society for Behavioral and Cognitive Neurology, 17(4), 195-200. 
Woods, S. P., Scott, J. C., Dawson, M. S., Morgan, E. E., Carey, C. L., Heaton, R. K., \& Grant, I. (2005). Construct validity of Hopkins Verbal Learning Test-Revised component process measures in an HIV-1 sample. Archives of Clinical Neuropsychology, 20(8), 1061-1071. doi:10.1016/j.acn.2005.06.007

Yepthomi, T., Paul, R., Vallabhaneni, S., Kumarasamy, N., Tate, D. F., Solomon, S., \& Flanigan, T. (2006). Neurocognitive consequences of HIV in southern India: A preliminary study of clade C virus. Journal of the International Neuropsychological Society, 12(3), 424-430. doi:10.1017/S1355617706060516 


\section{FIGURES.}

Figure 1. Predicted scores for Hopkins Verbal Learning Test-Revised (delayed) $(\mathrm{N}=322)$.

Figure 2. Predicted scores for Rey-Osterrieth Complex Figure Test (three-minute delayed recall) $(\mathrm{N}=322)$. 
Table 1. Demographic characteristics of the sample $(\mathrm{N}=322)$.

\begin{tabular}{cccccccc}
\hline \multirow{2}{*}{ Age group } & $\boldsymbol{n}(\%)$ & \multicolumn{2}{c}{ Age } & \multicolumn{2}{c}{ Education } & \multicolumn{2}{c}{ Gender } \\
\cline { 3 - 8 } & & Mean & SD & Mean & SD & Female & Male \\
\cline { 6 - 9 } & & & & & & $\boldsymbol{n}$ & $\boldsymbol{n}$ \\
\hline $20 \pm 2$ year & $41(12.7 \%)$ & 20.1 & 1.4 & 12.7 & 3.1 & 22 & 19 \\
\hline $25 \pm 2$ year & $62(19.3 \%)$ & 24.9 & 1.4 & 13.6 & 3.7 & 26 & 36 \\
\hline $30 \pm 2$ year & $30(9.3 \%)$ & 29.8 & 1.5 & 15.0 & 4.4 & 19 & 11 \\
\hline $35 \pm 2$ year & $30(9.3 \%)$ & 35.0 & 1.4 & 14.1 & 5.2 & 17 & 13 \\
\hline $40 \pm 2$ year & $26(8.1 \%)$ & 39.9 & 1.4 & 12.2 & 4.1 & 14 & 12 \\
\hline $45 \pm 2$ year & $26(8.1 \%)$ & 44.6 & 1.1 & 13.3 & 4.2 & 14 & 12 \\
\hline $50 \pm 2$ year & $20(6.2 \%)$ & 50.1 & 1.6 & 13.2 & 4.7 & 14 & 6 \\
\hline $55 \pm 2$ year & $20(6.2 \%)$ & 55.7 & 1.4 & 14.1 & 6.2 & 13 & 7 \\
\hline $60 \pm 2$ year & $16(5.0 \%)$ & 60.3 & 1.2 & 14.5 & 4.6 & 9 & 7 \\
\hline $65 \pm 2$ year & $13(4.0 \%)$ & 64.5 & 1.5 & 13.4 & 6.0 & 7 & 6 \\
\hline $70 \pm 2$ year & $11(3.4 \%)$ & 68.5 & 0.7 & 11.8 & 5.0 & 6 & 5 \\
\hline $75 \pm 2$ year & $11(3.4 \%)$ & 75.2 & 1.4 & 11.5 & 6.8 & 5 & 6 \\
\hline$>78$ year & $16(5.0 \%)$ & 81.2 & 1.9 & 9.6 & 3.7 & 8 & 8 \\
\hline Total & $\mathbf{3 2 2}(\mathbf{1 0 0 \% )}$ & $\mathbf{4 1 . 3}$ & $\mathbf{1 8 . 2}$ & $\mathbf{1 3 . 2}$ & $\mathbf{4 . 6}$ & $\mathbf{1 7 4}$ & $\mathbf{1 4 8}$ \\
\hline
\end{tabular}

Note. $\mathrm{SD}=$ Standard deviation 
Table 2. Pearson correlations coefficients between all scores and demographic variables $(\mathrm{N}=322)$.

\begin{tabular}{cccc}
\hline Score & Age & Education & Gender \\
\hline $\begin{array}{c}\text { HVLT-R } \\
\text { total recall }\end{array}$ & $-.466^{* * *}$ & $.305^{* * *}$ & -.006 \\
\hline $\begin{array}{c}\text { HVLT-R } \\
\text { delayed recall }\end{array}$ & $-.450^{* * *}$ & $.309^{* * *}$ & -.101 \\
\hline $\begin{array}{c}\text { HVLT-R } \\
\text { recognition }\end{array}$ & $-.199^{*}$ & $.167^{* *}$ & -.080 \\
\hline $\begin{array}{c}\text { ROCF } \\
\text { copy }\end{array}$ & $-.382^{* * *}$ & $.281^{* * *}$ & $4.9 \mathrm{E}-04$ \\
\hline $\begin{array}{c}\text { ROCF } \\
\text { three-minute delayed recall }\end{array}$ & $-.495^{* * *}$ & $.294^{* * *}$ & .098 \\
\hline
\end{tabular}

Note. ${ }^{* * *}=p<0.001 ; * *=p<0.01 ; *=p<0.05$.

Note. HVLT-R = Hopkins Verbal Learning Test-Revised; ROCF = Rey-Osterrieth Complex Figure Test. 
Table 3. Final multiple linear regression models for Hopkins Verbal Learning Test-Revised $(\mathrm{N}=322)$.

\begin{tabular}{|c|c|c|c|c|c|c|c|}
\hline Score & Variable & B & Std. Error & Stand. B & $\mathbf{t}$ & Sig. & Adjusted $\mathrm{R}^{2}$ \\
\hline \multirow{3}{*}{$\begin{array}{l}\text { HVLT-R } \\
\text { total recall }\end{array}$} & Constant & 21.686 & .229 & & 94.554 & $<.001$ & \multirow{3}{*}{.274} \\
\hline & Age & -.115 & .013 & -.434 & -9.051 & $<.001$ & \\
\hline & Education & .264 & .051 & .250 & 5.224 & $<.001$ & \\
\hline \multirow{5}{*}{$\begin{array}{c}\text { HVLT-R } \\
\text { delayed } \\
\text { recall }\end{array}$} & Constant & 7.97 & .155 & & 51.411 & $<.001$ & \multirow{5}{*}{.299} \\
\hline & Age & -.060 & .006 & -.446 & -9.313 & $<.001$ & \\
\hline & Education & .165 & .026 & .312 & 6.329 & $<.001$ & \\
\hline & Gender & -.715 & .228 & -.147 & -3.131 & .002 & \\
\hline & Age X Edu & -.004 & .001 & -.144 & -2.893 & .004 & \\
\hline \multirow{2}{*}{$\begin{array}{l}\text { HVLT-R } \\
\text { recognition }\end{array}$} & Constant & 10.937 & .111 & & 98.642 & $<.001$ & \multirow{2}{*}{.025} \\
\hline & Education & .073 & .024 & .167 & 3.023 & .003 & \\
\hline
\end{tabular}

Note. HVLT-R = Hopkins Verbal Learning Test-Revised 
Table 4. Final multiple linear regression models for Rey-Osterrieth Complex Figure Test $(\mathrm{N}=322)$.

\begin{tabular}{|c|c|c|c|c|c|c|c|}
\hline Score & Variable & B & Std. Error & Stand. B & $\mathbf{t}$ & Sig. & Adjusted $R^{2}$ \\
\hline \multirow{4}{*}{ ROCF copy } & Constant & 31.476 & .425 & & 74.13 & $<.001$ & \multirow{4}{*}{.224} \\
\hline & Age & -.076 & .020 & -.231 & -3.842 & $<.001$ & \\
\hline & $\mathrm{Age}^{2}$ & -.003 & .001 & -.216 & -3.556 & $<.001$ & \\
\hline & Education & .273 & .065 & .210 & 4.189 & $<.001$ & \\
\hline \multirow{3}{*}{$\begin{array}{l}\text { ROCF } \\
\text { three-minute } \\
\text { delayed recall }\end{array}$} & Constant & 18.326 & .36 & & 50.965 & $<.001$ & \multirow{3}{*}{.295} \\
\hline & Age & -.197 & .02 & -.466 & -9.86 & $<.001$ & \\
\hline & Education & .394 & .079 & .235 & 4.974 & $<.001$ & \\
\hline
\end{tabular}

Note. $\mathrm{ROCF}=$ Rey-Osterrieth Complex Figure Test. 


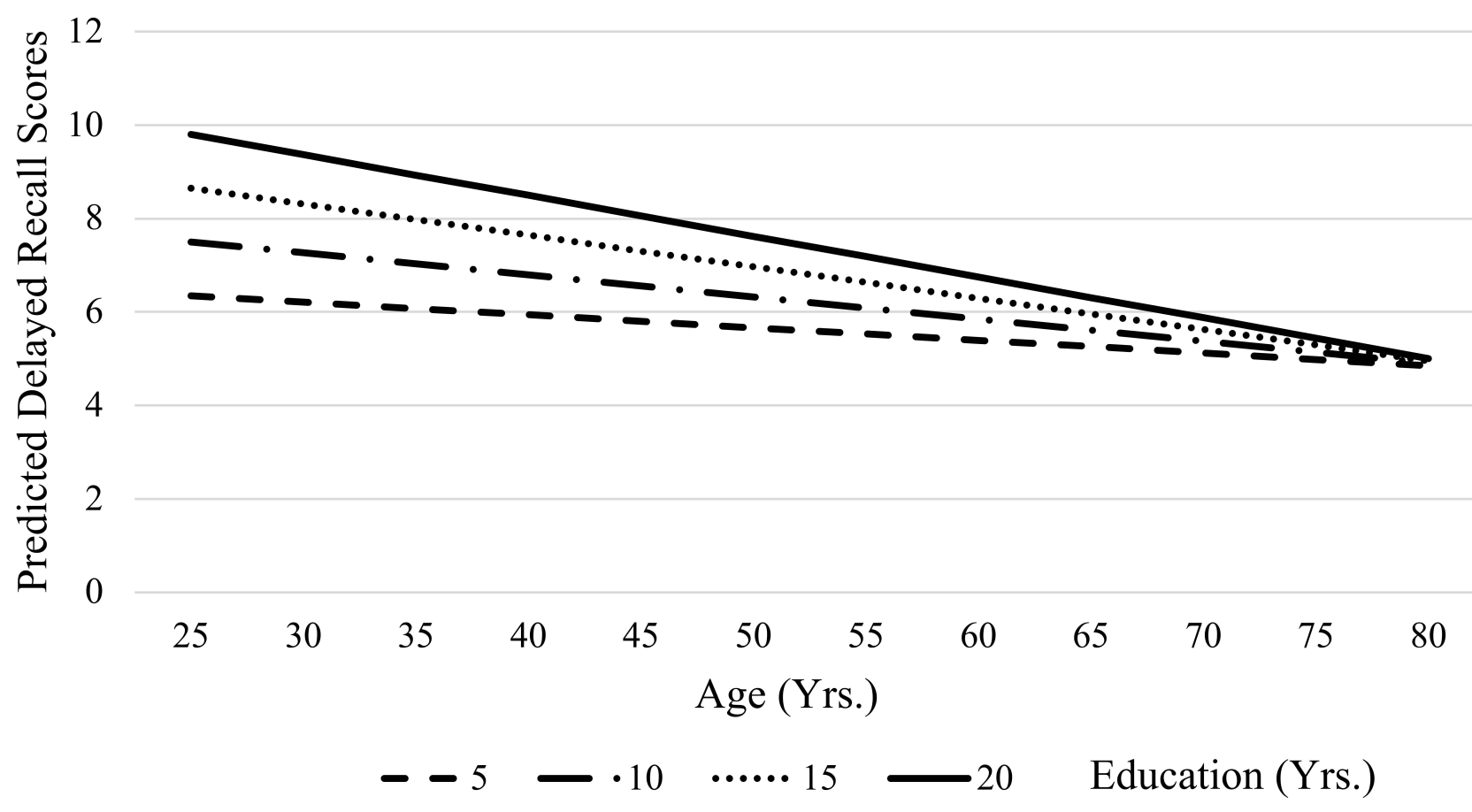




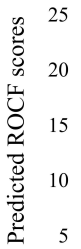

0

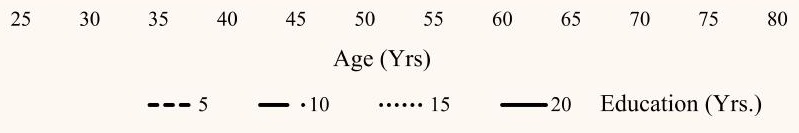

